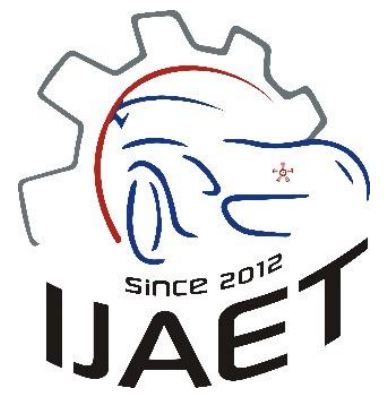

e-ISSN: 2146 - 9067

International Journal of Automotive

Engineering and Technologies

journal homepage:

https://dergipark.org.tr/en/pub/ijaet

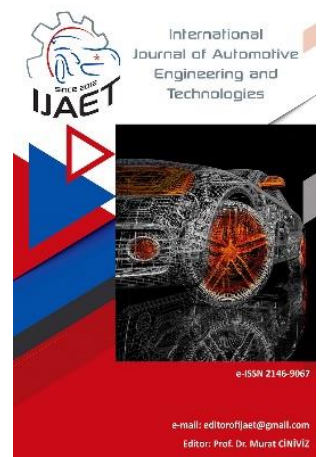

Original Research Article

\title{
Experimental performance evaluation of an R1234yf automobile air conditioning system employing an internal heat exchanger
}

\author{
Umut Gungor ${ }^{1}$, Murat Hosoz ${ }^{2}$ * \\ ${ }^{1}$ Graduate School of Natural and Applied Sciences, Kocaeli University, Kocaeli, 41001, Turkey \\ 2, * Department of Automotive Engineering, Kocaeli University, Kocaeli, 41001, Turkey
}

\begin{tabular}{l} 
ARTICLE INFO \\
\hline 1. 0000-0002-9844-7681 \\
2. 0000-0002-3136-9586
\end{tabular}

Doi: $10.18245 /$ ijaet. 842426

* Corresponding author mhosoz@kocaeli.edu.tr

Received: Dec 17, 2020

Accepted: Feb 26, 2021

Published: Mar 31, 2021

Published by Editorial Board Members of IJAET

(C) This article is distributed by Turk Journal Park System under the CC 4.0 terms and conditions.

\begin{abstract}
A bench-top automobile air conditioning (AAC) system using a thermostatic expansion valve was developed. The system was equipped with a coaxial internal heat exchanger (HEX) and charged with R1234yf, a new refrigerant used as an alternative to R134a. The system was tested at the compressor speeds ranging between $1000 \mathrm{rpm}$ and $2600 \mathrm{rpm}$ with increments of $400 \mathrm{rpm}$. For each compressor speed, the air temperatures at the evaporator and condenser inlets were concurrently changed between $30{ }^{\circ} \mathrm{C}$ and $40{ }^{\circ} \mathrm{C}$ with increments of $5{ }^{\circ} \mathrm{C}$. The system was operated for the cases of employing and not employing the HEX, and totally 30 test runs were performed. Then, the first law of thermodynamics was applied to the system components to evaluate various steady state performance parameters. The considered parameters were the refrigerant mass flow rate, evaporating temperature, cooling capacity, compressor power, coefficient of performance (COP), condenser heat dissipation rate and discharge temperature of the compressor. It was determined that the experimental system employing the HEX yielded on average $0.8{ }^{\circ} \mathrm{C}$ lower evaporating temperature, $2.2 \%$ higher cooling capacity, $2.0 \%$ lower compressor power and 3.0\% higher COP values relative to the system not employing the HEX. These findings reveal that the use of HEX causes a better system performance in terms of the cooling capacity, compressor power and COP. Consequently, the performance of R1234yf AAC systems can be improved with the use of HEX, and thus, the AAC systems using R1234yf can be more competitive with those using R134a.

Keywords: Automobile, air conditioning, R1234yf, heat exchanger
\end{abstract}

\section{Introduction}

Automobile air conditioning (AAC) systems using vapour compression refrigeration cycles were initially developed in 1930s. R12, a refrigerant from Chlorofluorocarbon (CFC) group was the first refrigerant employed in AAC systems. Then, in 1970s, it was determined that the chlorine atoms in CFC molecules depleted the Ozone layer when they leaked into the atmosphere. Therefore, the Montreal Protocol in 1987 restricted the use of R12 in AAC systems [1]. Consequently, automotive manufacturers replaced R12 with $\mathrm{R} 134 \mathrm{a}$, a refrigerant from hydrofluorocarbon group. However, the global warming potential (GWP) of R134a is1430 [2], and European Union has restricted the use of refrigerants having a GWP of over 150 since 2017 [3]. Therefore, manufactures started to use 
R1234yf, an alternative refrigerant from Hydrofluoroolefin family.

Since the development of R1234yf as an alternative to R134a, many investigators have studied its comparative experimental performance. Zilio et al. determined that an experimental AAC unit with R1234yf yielded about $19 \%$ less cooling capacity than the unit with R134a [4]. Then, they investigated the ways to improve the performance of the R1234yf AAC unit and to make it equal to that of an R134a AAC one. They found that the R1234yf AAC unit could yield the same cooling capacity with the R134a one by making modifications in the system components. Zhao et al. also tested R1234yf in an R134a AAC unit and obtained $12.4 \%$ lower cooling capacity and 9\% lower coefficient of performance (COP) relative to R134a [5]. Similarly, Mota-Babiloni et al. investigated experimental performance of an R134a AAC unit using R1234yf. They found that the unit using R1234yf had lower cooling capacity and COP by $9 \%$ and $11 \%$, respectively, relative to the unit using R134a [6]. Meng et al. evaluated the performance of an AAC system employing an R1234yf/R134a mixture instead of R134a [7]. The system was operated in both cooling and heat pump modes and yielded 4$16 \%$ and $4-9 \%$ lower COPs in these modes, respectively. $\mathrm{Li}$ et al. investigated the performance of R134a and R1234yf in a refrigeration circuit using an oil-free linear compressor [8]. They determined that the R1234yf system resulted in 20\% lower COP relative to the R134a one. Aral et al. developed an experimental AAC system and investigated its comparative cooling and heat pump performance for the cases of R134a and R1234yf [9]. They found that the R1234yf system yielded $5.8 \%$ lower cooling capacity and $11.9 \%$ lower COP for cooling than the R134a one. Furthermore, the R1234yf system resulted in $0.2 \%$ higher heating capacity and $3.6 \%$ lower COP for heating than the R134a one.

Because AAC systems using R1234yf yield lower experimental performance relative to the ones using R134a, in search of improving the performance, investigators have employed an internal heat exchanger (HEX) between the liquid and suction lines of the refrigeration circuit of AAC systems. With the use of a HEX, it is expected that the refrigerant stream leaving the condenser furtherly rejects heat to the refrigerant stream leaving the evaporator, thus entering the expansion device at a lower temperature and enthalpy. Because the throttling process in the expansion device occurs at constant enthalpy, the refrigerant stream enters the evaporator at a lower vapour quality and enthalpy as well, thus it can absorb more heat in the evaporator compared to the system not using a HEX. Consequently, it is expected that an AAC system with a HEX will have a higher cooling capacity and COP.

Cho et al. determined that the cooling capacity and COP of an R1234yf AAC system not using an internal HEX were up to $7 \%$ and $4.5 \%$ lower than those of the R134a system, respectively [10]. However, when an internal HEX was used, the cooling capacity and COP of the R1234yf system were only up to $1.8 \%$ and $2.9 \%$ lower than those of the R134a one, respectively. Navarro-Esbri et al. installed an internal HEX on a conventional R134a AAC unit and studied the performance of R1234yf in this unit [11]. They found that the R1234yf unit yielded 6$13 \%$ lower cooling capacity and COP when the HEX was not employed. However, the R1234yf system resulted in only 2-6\% lower cooling capacity and COP when the HEX was employed. Direk et al. studied the performance of an R134a AAC unit employing a HEX and using R1234yf [12]. They determined that the use of HEX significantly enhanced the cooling capacity and COP. Wantha developed an AAC system using a HEX and investigated its effect on the system performance for R134a and R1234yf [13]. He found that the use of HEX caused $2.11 \%$ and $3.78 \%$ improvements in the COP for the system using R134a and R1234yf, respectively. Direk and Kelesoglu developed an R1234yf AAC system and installed a doublepipe internal HEX on it to improve its performance [14]. They found that the use of HEX caused an increase in the COP by $6 \%$ and a decrease in the total exergy destruction per unit cooling capacity by $16 \%$. Direk et al also found that the use of HEX improved the exergetic efficiency of the AAC system with R1234yf [15]. Oruç and Devecioğlu employed two types of internal HEXs, namely tube-intube and brazed plate types, in a refrigeration system using refrigerants R404A and R442A [16]. They found that both types of HEXs 
caused improvements in the energy performance of the system for both refrigerants although the brazed plate HEX yielded a higher performance improvement. Prabakaran et al. investigated the effect of thermostatic expansion valve tuning, i.e. superheat adjustment, on the performance of an AAC system with a HEX using refrigerants R134a and R1234yf [17]. They concluded that the R1234yf AAC system using HEX with superheat adjustment enhanced the performance and made the system a sound alternative to the R134a one.

Besides experimental studies, some investigators studied theoretical performance of vapour compression refrigeration systems and AAC units using various software. Yataganbaba et al. presented theoretical exergy analysis of a vapor-compression refrigeration circuit for refrigerants R134a, R1234yf and R1234ze(E) [18]. They concluded that both R1234yf and $\mathrm{R} 1234 \mathrm{ze}(\mathrm{E})$ were appropriate alternatives of R134a. Vaghela investigated the theoretical performance of various R134a alternatives, namely R290, R600a, R407C, R410A, R404A, R152a and R1234yf, by using Engineering Equation Solver and REFPROP software [19]. He found that the best alternative of R134a was R1234yf although it had slightly lower performance. Gaurav and Kumar tested 31 refrigerants and refrigerant mixtures as alternatives of R134a [20]. Although they determined that R290 yielded the highest COP, it was not a decent alternative due to its high flammability. They suggested 40\%R134a/22\%R1234yf/38\% R1234ze mixture as the best alternative of R134a. Qi theoretically studied the thermodynamic performance of an AAC system using R1234yf [21]. They determined $15 \%$ improvement in the COP when the condenser subcooling was increased from $1 \mathrm{~K}$ to $10 \mathrm{~K}$ at a constant compressor power. Daviran et al. simulated an R1234yf AAC system by means of MATLAB and REFPROP software [22]. They determined that the R1234yf system yielded 1.3-5\% lower $\mathrm{COP}$ relative to the $\mathrm{R} 134 \mathrm{a}$ one. Belman-Flores and Ledesma developed a model for an R1234yf refrigeration circuit using artificial neural network and obtained model results close to the experimental ones [23]. Hosoz et al. studied a model for an AAC system using support vector regression technique [24] and obtained encouraging model results in full agreement with the experimental ones. Mendoza-Miranda et al. modelled a variable speed liquid chiller for R134a and R1234yf [25]. They found that the use of R1234yf caused $2.0-11.3 \%$ reduction in the COP relative to R134a. Direk et al. theoretically investigated the effects of a HEX on various performance parameters of a vapourcompression refrigeration circuit using R1234yf [26]. They compared the R1234yf results obtained with HEX and the R134a ones of the baseline circuit obtained without HEX. They determined that that the critical HEX effectiveness yielding the same COP with the R134a baseline circuit was $50 \%$.

Some investigators compared experimental performance of R1234yf and R134a when they were used in automotive heat pump (AHP) systems. Direk and Yuksel evaluated energy performance of an AHP for refrigerants R134a and R1234yf, finding that the system with R134a provided higher heating capacity and COP than that with R1234yf [27]. Alkan et al. investigated energetic and exergetic performance of an AHP using R1234yf and R134a [28]. They found that the R1234yf resulted in significantly less total equivalent warming impact but less heating capacity, less COP and higher total exergy destruction rate per unit heating capacity relative to R134a. Tasdemirci et al. developed an experimental AHP system employing a coaxial HEX and evaluated its various performance parameters for both refrigerants and cases of using and not using the HEX [29]. They determined that the R1234yf system with HEX yielded averagely $13.9 \%$ lower heating capacity but $7.8 \%$ higher COP in comparison to the R134a one.

The literature survey reveals that experimental studies on R1234yf AAC systems usually compared several performance parameters of the system with those of the R134a one under a narrow range of test conditions. In this study, as a contribution to literature, energetic performance parameters of an R1234yf system using an internal HEX were evaluated in comparison with the same system not using the HEX to investigate the impact of HEX on the system performance. Although the studies in the literature were performed for a few compressor speeds and entering air temperatures, the experimental comparisons presented in this 


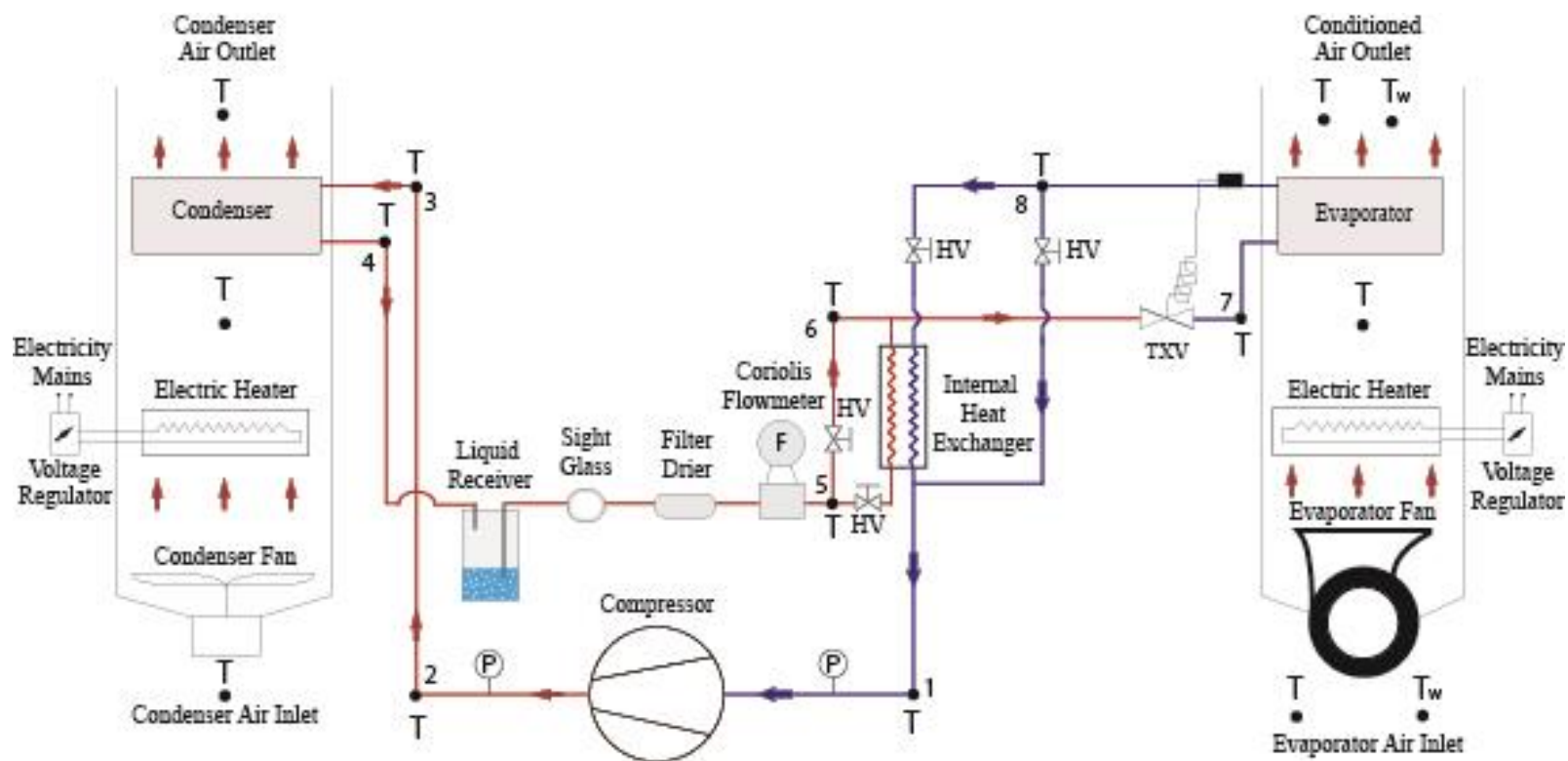

Figure 1. Schematic view of the experimental AAC unit

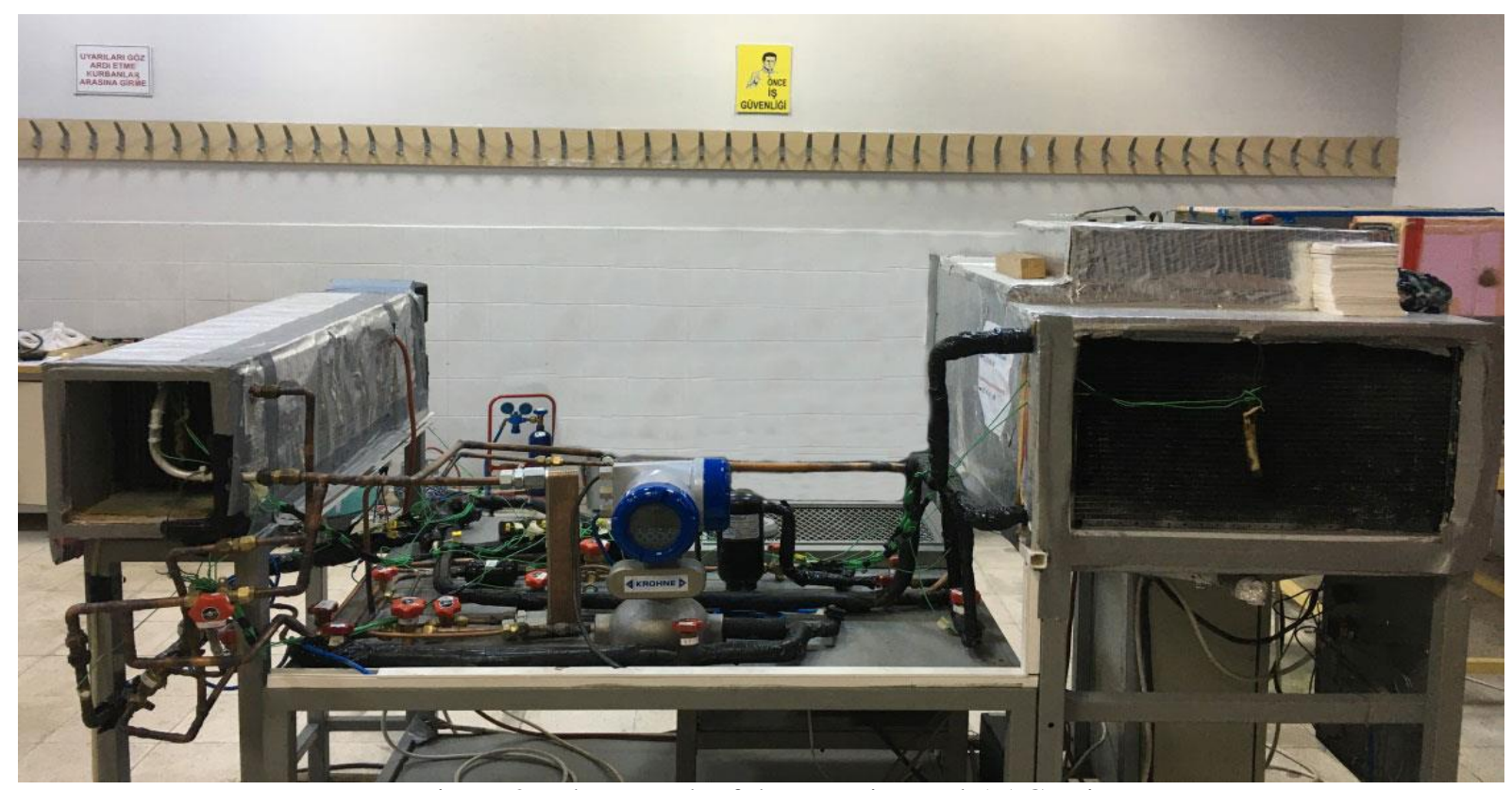

Figure 2. Photograph of the experimental AAC unit

paper were based on tests performed under wide ranges of compressor speed and entering air temperature. The considered performance parameters were the refrigerant mass flow rate, evaporating temperature, cooling capacity, compressor power, COP, condenser heat dissipation rate and compressor discharge temperature. These parameters were reported in comparative graphics for the cases of using and not using the HEX.

\section{Materials and Methods}

2.1. Experimental automobile air conditioning system

In this work, a bench-top AAC system was developed and equipped with a coaxial internal
HEX. The refrigeration cycle of the AAC system contains a laminated evaporator, microchannel condenser, fixed-capacity swash-plate compressor, thermostatic expansion valve (TXV), liquid receiver, filter/drier, sight glass, internal HEX and hand valves (HVs). The sketch of the experimental AAC system was indicated in Figure 1, while its photograph was provided in Figure 2.

The compressor was energised by a three-phase electric motor through a frequency inverter providing operations at the desired compressor speeds. The condenser and evaporator were placed into $1 \mathrm{~m}$ long air ducts. The condenser and evaporator air streams were obtained by an axial fan and centrifugal fan, respectively. 
During the tests, both fans were operated at their maximum speeds. The average air speeds passing over the condenser and evaporator were $3.1 \mathrm{~m} / \mathrm{s}$ and $2.1 \mathrm{~m} / \mathrm{s}$, respectively. To adjust the temperatures of the air streams entering the condenser and evaporator to the desired values, two separate electric heaters were employed in the air ducts. The heating capacity of the heater in the condenser duct was $5.6 \mathrm{~kW}$ while that in the evaporator duct was $1.8 \mathrm{~kW}$. These heaters were energised through potentiometers to operate the system at the desired inlet air temperatures. $2200 \mathrm{~g}$ of R1234yf and $200 \mathrm{cc}$ of PAG type compressor oil were charged into the experimental unit. This refrigerant charge was the minimum one providing subcooled refrigerant at the condenser outlet and superheated refrigerant at the evaporator outlet in the entire range of the tests.

Numerous mechanical measurements were performed on the experimental unit to evaluate its performance. Bourdon tube manometers were used for measuring the refrigerant pressures sucked into and discharged from the compressor. Because the pressure drops in the refrigerant lines and HEX were ignored, the evaporator and condenser pressures were accepted to be equal to the compressor suction and discharge pressures, respectively. The temperatures of the refrigerant incoming and leaving each component were measured by type $\mathrm{K}$ thermocouples. A Coriolis flow meter installed in the liquid line was used for measuring the refrigerant mass flow rate. A photoelectric tachometer measured the compressor speed. Type $\mathrm{K}$ thermocouples were used for monitoring the air dry and wet-bulb temperatures incoming and leaving the evaporator duct. Furthermore, type K thermocouples also served for monitoring the air dry-bulb temperatures incoming and leaving the condenser duct. The air temperatures leaving the heaters and incoming the evaporator and condenser were measured by type $\mathrm{K}$ thermocouples as well. The locations of all instruments were shown in Figure 1. The instrument characteristics were provided in Table 1.

\subsection{Test procedure}

The developed AAC unit was tested for the cases of employing and not employing the internal HEX. In the tests, the unit was operated at five compressor speeds, namely 1000, 1400, 1800, 2200 and $2600 \mathrm{rpm}$. The air temperatures incoming the evaporator and condenser were concurrently adjusted to $30^{\circ} \mathrm{C}, 35^{\circ} \mathrm{C}$ and $40^{\circ} \mathrm{C}$ for each compressor speed. Thus, 15 tests were conducted for the case of not using the internal HEX, while another 15 tests were conducted for the case of using the internal HEX. The HEX was activated by opening its HVs and closing the HVs in the by-pass lines. The system performance was evaluated based on the steadystate test data. When the changes in the refrigerant temperatures entering and leaving the compressor were within $\pm 1^{\circ} \mathrm{C}$ for 2 minutes, the system was assumed to operate in steadystate. Then, the data were collected for the performance evaluation.

Table 1. Characteristics of the instruments

\begin{tabular}{|c|c|c|c|}
\hline $\begin{array}{l}\text { Measured } \\
\text { Parameter }\end{array}$ & Instrument & Range & Accuracy \\
\hline Pressure & $\begin{array}{l}\text { Bourdon } \\
\text { manometer }\end{array}$ & $\begin{array}{l}-1 / 10,0 / 30 \\
\text { bar }\end{array}$ & $\begin{array}{l} \pm 0.1 / 0.5 \\
\text { bar }\end{array}$ \\
\hline Temperature & $\begin{array}{l}\text { Type K } \\
\text { thermocouple }\end{array}$ & $-50 / 500^{\circ} \mathrm{C}$ & $\pm 0.5^{\circ} \mathrm{C}$ \\
\hline $\begin{array}{l}\text { Compressor } \\
\text { speed }\end{array}$ & $\begin{array}{l}\text { Photoelectric } \\
\text { tachometer }\end{array}$ & $\begin{array}{l}10 / 999999 \\
\text { rpm }\end{array}$ & $\pm \% 0.1$ \\
\hline $\begin{array}{l}\text { Refrigerant } \\
\text { flow rate }\end{array}$ & $\begin{array}{l}\text { Coriolis mass } \\
\text { flow meter }\end{array}$ & $0 / 350 \mathrm{~kg} / \mathrm{h}$ & $\pm \% 0.1$ \\
\hline Air speed & $\begin{array}{l}\text { Vane } \\
\text { anemometer }\end{array}$ & $0.1 / 15 \mathrm{~m} / \mathrm{s}$ & $\pm \% 3$ \\
\hline
\end{tabular}

\section{Thermodynamic Analysis}

Assuming that the changes in the kinetic and potential energies are negligible, the first law of thermodynamics was applied to each component of the unit. In the first law analysis, the enthalpies of the refrigerant at the numbered points of the circuit were required. These enthalpies were determined from REFPROP 9.1 software [30] using the refrigerant pressure and temperature data.

The cooling capacity of the unit was determined from

$\dot{Q}_{\text {evap }}=\dot{m}_{r}\left(h_{8}-h_{7}\right)$

where $\dot{m}_{r}$ is the refrigerant mass flow rate, and $h_{8}$ and $h_{7}$ are the refrigerant enthalpies leaving and entering the evaporator, respectively.

Assuming that the compressor operated adiabatically, the compressor power transferred to the refrigerant was evaluated from

$\dot{W}_{\text {comp }}=\dot{m}_{r}\left(h_{2}-h_{1}\right)$

where $h_{2}$ and $h_{1}$ are the refrigerant enthalpies at 
the outlet and inlet of the compressor, respectively.

The cooling capacity per unit compressor power yielded the coefficient of performance for the system, i.e.

COP $=\dot{Q}_{\text {evap }} / \dot{W}_{\text {comp }}$

Finally, the heat dissipation into the ambient air in the condenser was calculated from

$\dot{Q}_{\text {cond }}=\dot{m}_{r}\left(h_{3}-h_{4}\right)$

where $h_{3}$ and $h_{4}$ are the refrigerant enthalpies at the inlet and outlet of the condenser, respectively.

\section{Uncertainty Analysis}

The uncertainties of the performance parameters of the AAC system calculated by Equations (14) can be determined by using the Moffat method [31]. In this method, the uncertainty of the calculated $Y$ parameter, which is a function of totally $N$ measured variables defined as $X_{1}$, $X_{2}, \ldots, X_{n}$, can be evaluated from

$\delta Y=\sqrt{\sum_{i=1}^{N}\left(\frac{\partial Y}{\partial X_{i}} \delta_{X_{i}}\right)^{2}}$

where $\delta_{X_{i}}$ indicates the accuracy of the measured variable. Using the accuracies of the measured variables reported in Table 1 and test data, the uncertainties of the calculated parameters were determined from Equation (5) with the help of Engineering Equation Solver software [32]. The maximum values of the total uncertainties for the cooling capacity, compressor power, COP and condenser heat rejection rate were estimated to be $\pm 0.049 \mathrm{~kW}$, $\pm 0.033 \mathrm{~kW}, \pm 0.099$ and $\pm 0.038 \mathrm{~kW}$, respectively.

\section{Results and Discussion}

Significant performance parameters of the experimental system with R1234yf were shown in Figures 3-9 for the cases of employing and not employing the internal HEX.

The mass flow rate of the circulated refrigerant was shown in Figure 3. It gets higher on rising the compressor speed and air temperatures incoming the evaporator and condenser no matter if the HEX is employed or not. On the other hand, the refrigerant temperature entering the compressor increases when the HEX is employed. Because the density of the refrigerant decreases with rising temperature, the compressor volumetric efficiency drops. Consequently, due to the lowered compressor volumetric efficiency experienced in the operations with the HEX, the AAC unit employing the HEX resulted in averagely $5.4 \%$ lower refrigerant mass flow rate relative to the unit not employing it.

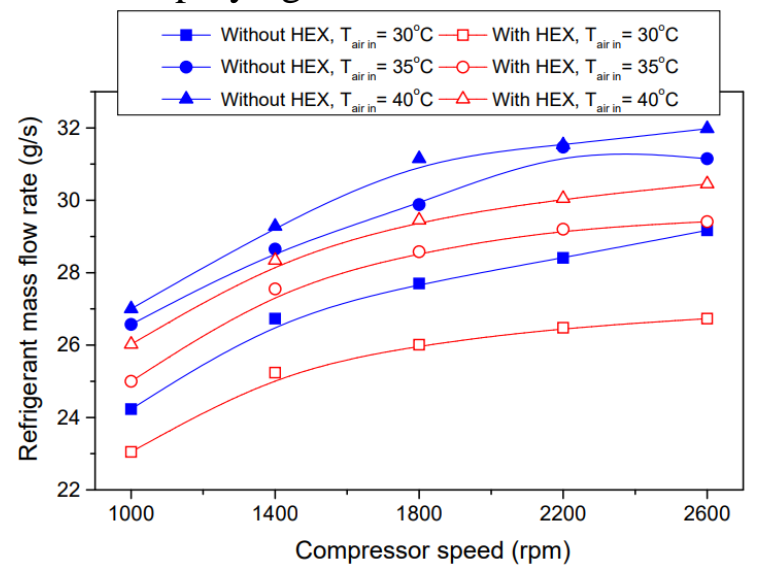

Figure 3. Refrigerant mass flow rate vs. compressor speed

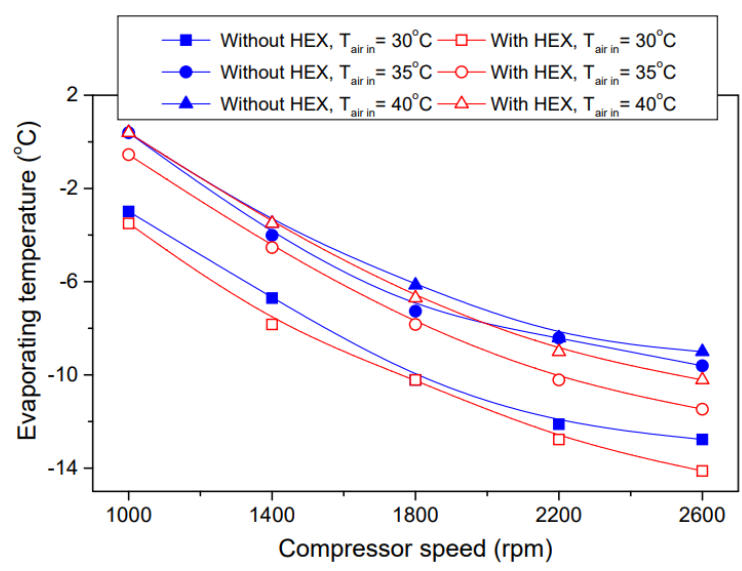

Figure 4. Evaporating temperature vs. compressor speed

The evaporating temperature of the refrigerant was exhibited in Figure 4. The evaporating temperature decreases on rising the compressor speed due to the dropping compressor suction pressure. Furthermore, it decreases with dropping entering air temperatures for the system with and without the HEX. Because the use of HEX causes a drop in the refrigerant mass flow rate, both the evaporating pressure and temperature also drop. Furthermore, the refrigerant enters the TXV at a lower temperature when the HEX is employed. Consequently, the AAC system employing the HEX resulted in averagely $0.8{ }^{\circ} \mathrm{C}$ lower evaporating temperature compared with the system without the HEX.

Figure 5 reports the cooling capacity of the 
experimental unit. It increases on increasing the compressor speed and entering air temperatures no matter if the HEX is employed or not. On the other hand, both the refrigerant temperature at the TXV inlet and the evaporating temperature are lower when the HEX is used. Then, the temperature difference between the refrigerant and air streams increases, and the refrigerant can absorb more heat in the evaporator despite dropping refrigerant mass flow rate experienced with the use of HEX. As a result, the AAC system employing the HEX resulted in averagely $2.2 \%$ higher cooling capacity than the system not employing it.

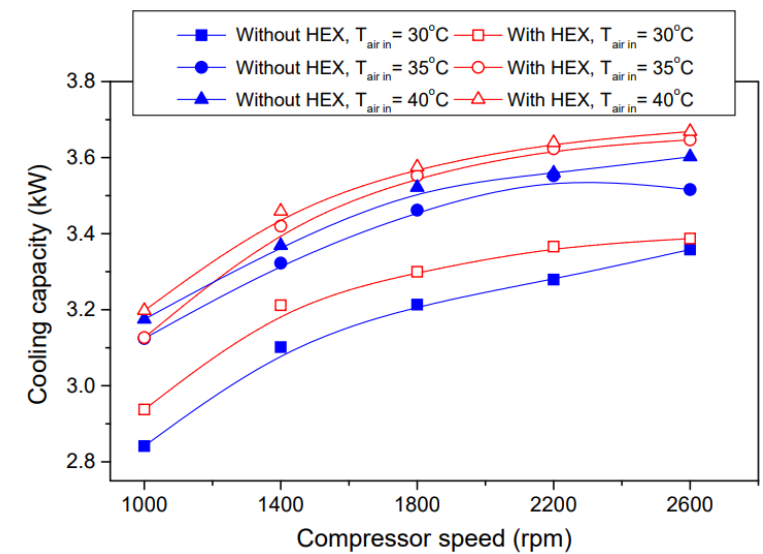

Figure 5. Cooling capacity vs. compressor speed

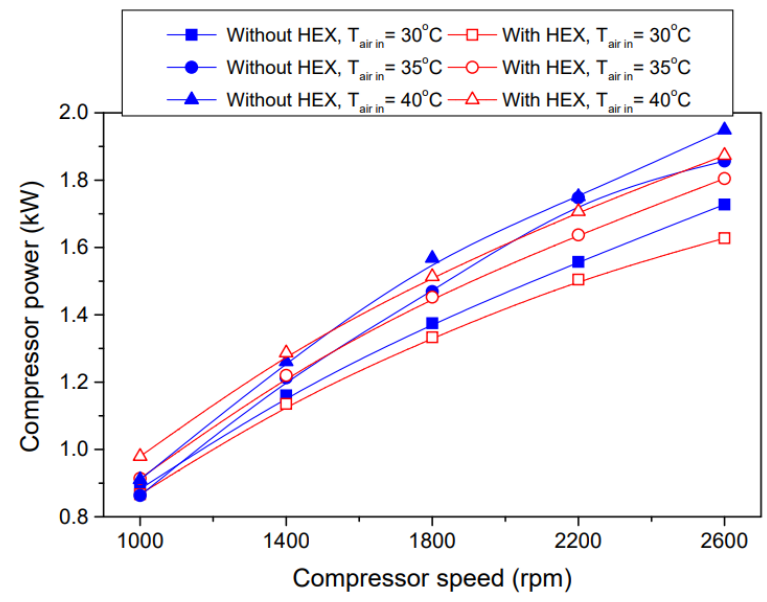

Figure 6. Compressor power vs. compressor speed

The compressor power was reported in Figure 6. It increases on increasing the compressor speed and entering air temperatures for both cases of employing and not employing the HEX. On the other hand, the operation with the HEX causes less refrigerant mass flow rate, which supresses the compressor power. Although it is not graphically shown, the use of HEX also causes higher compressor pressure ratio, which promotes the compressor power. Because the refrigerant mass flow rate is more influential than the pressure ratio, the compressor power drops with the use of HEX. The AAC system employing the HEX resulted in averagely $2.0 \%$ lower compressor power than the one not employing it.

The COP for the AAC unit was exhibited in Figure 7. COP is defined as the ratio of the cooling capacity to the compressor power. Since the cooling capacity increases more slowly than the compressor power does with the compressor speed, COP drops on increasing the compressor speed. Furthermore, it decreases on increasing the entering air temperatures no matter if the HEX is employed or not. The AAC system with the HEX usually provides higher cooling capacity but consumes lower compressor power. Consequently, the COP for the system employing the HEX was averagely $3.0 \%$ higher than that not employing the HEX. In other words, use of HEX promotes the energy effectiveness of the AAC system.

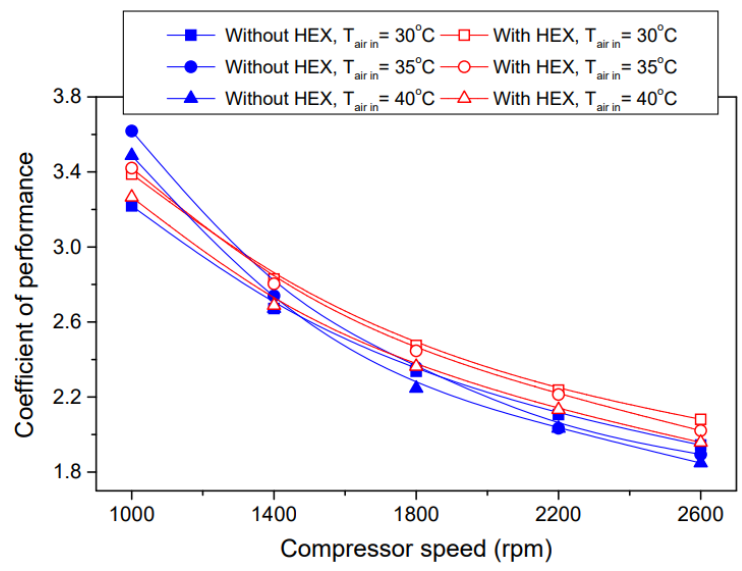

Figure 7. Coefficient of performance vs. compressor speed

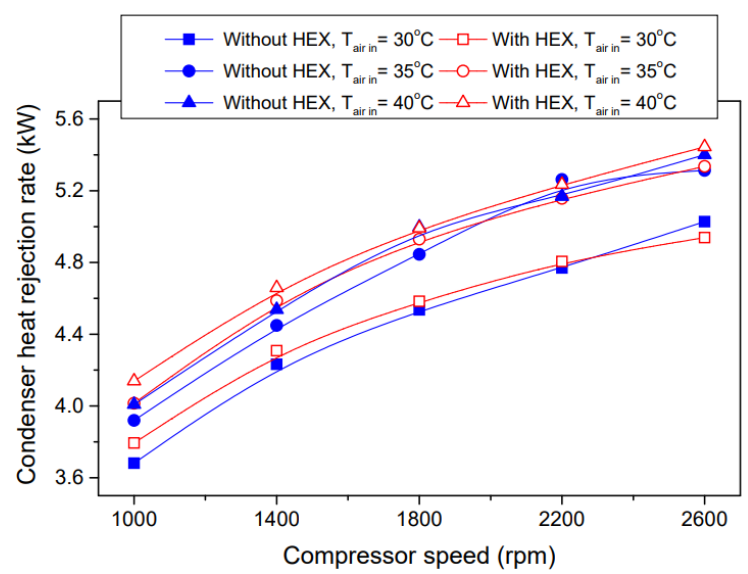

Figure 8. Condenser heat rejection rate vs. compressor speed

The heat rejected in the condenser of the experimental system was reported in Figure 8. The condenser heat dissipation rate increases on 
increasing the compressor speed and entering air temperatures no matter if the HEX is employed or not. The summation of the compressor power and cooling capacity yields the condenser heat dissipation rate. As observed before, the system with the HEX has a higher cooling capacity but a lower compressor power. In some tests the effect of the former overweighed the latter, while the effect of the latter overweighed the former in others. Consequently, under certain conditions the AAC system with the HEX yielded higher condenser heat dissipation rate, while under others the system without the HEX resulted in higher dissipation rates. The AAC unit employing the HEX resulted in averagely $1.1 \%$ higher condenser heat dissipation rate than the one not employing it.

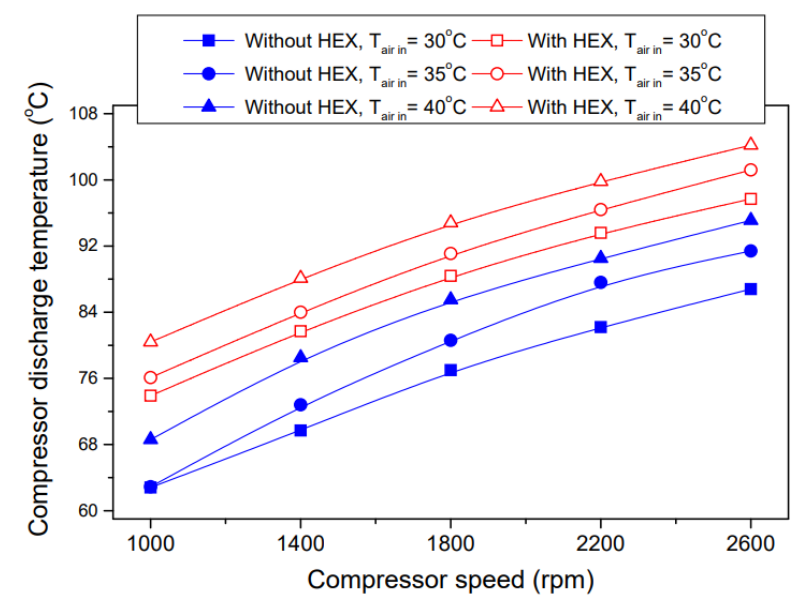

Figure 9. Compressor discharge temperature vs. compressor speed

The temperature of the refrigerant discharged from the compressor was reported in Figure 9. The elevated compressor discharge temperatures have deteriorative effects on the compressor oil, which boosts the friction in the compressor and shortens its service lifetime. On the other hand, low compressor discharge temperatures cause a decrease in the condenser heat dissipation rate. The compressor discharge temperature increases on increasing the compressor speed and temperatures of the entering air streams. Because the use of HEX promotes the temperature of the refrigerant incoming the compressor, the temperature of the refrigerant exiting the compressor increases as well. Consequently, the AAC system with the HEX yielded an average compressor discharge temperature of $90.1{ }^{\circ} \mathrm{C}$, while that without the HEX resulted in an average compressor discharge temperature of $79.5^{\circ} \mathrm{C}$.

\section{Conclusions}

An experimental AAC system with a TXV and using R1234yf was set up and equipped with a coaxial internal HEX. Then, it was tested in wide ranges of compressor speed and entering air temperatures for the cases of employing and not employing the HEX. Next, the first law of thermodynamics was applied to the components of the AAC system, and its various steady state performance parameters were evaluated. The important results reached in this investigation are reported below.

- The operations with the HEX caused on average 5.4\% lower refrigerant mass flow rate than the operations without the HEX.

- The operations with the HEX resulted in on average $0.8{ }^{\circ} \mathrm{C}$ lower evaporating temperature than those without the HEX.

- The operations with the HEX provided averagely $2.2 \%$ higher cooling capacity compared to those without the HEX.

- The operations with the HEX caused on average $2.0 \%$ lower compressor power than those without the HEX.

- The operations with the HEX yielded averagely $3.0 \%$ higher COP values than those without the HEX.

- The operations with the HEX caused on average $1.1 \%$ higher condenser heat rejection rate relative to those without the HEX.

- With the use of HEX, the compressor discharge temperature was on average $10.6{ }^{\circ} \mathrm{C}$ higher than that observed in the system without the HEX.

These findings indicate that the use of HEX causes a better system performance when the cooling capacity, compressor power and COP are taken into consideration. Thus, poorer performance of R1234yf AAC systems reported in the literature can be improved with the use of HEX. The effects of various types of internal heat exchangers on the system performance can be investigated as a future study.

\section{References}

1. UNEP, "Montreal Protocol on substances that deplete the ozone layer, final act", United Nations Environment Programme, 1987.

2. Lee, Y. and Jung, D., "A brief performance comparison of R1234yf and R134a in a bench tester for automobile applications", 
Applied Thermal Engineering, 35, 240-242, 2012.

3. EU, "Regulation (EU) No 517/2014 of the European Parliament and of the Council of 16 April 2014 on fluorinated greenhouse gases and repealing Regulation (EC) No 842/2006", Official Journal of European Union, L 150/195, 2014.

4. Zilio, C., Brown, S.J., Schiochet, G. and Cavallini, A., "The refrigerant R1234yf in air conditioning systems", Energy, 36(10), 61106120, 2011.

5. Zhao, Y., Qi, Z., Chen, J., Xu, B. and He, B., "Experimental analysis of the low-GWP refrigerant R1234yf as a drop-in replacement for $\mathrm{R} 134 \mathrm{a}$ in a typical mobile air conditioning system", Journal of Mechanical Engineering Science, 226, 2713-2725, 2012.

6. Mota-Babiloni, A., Navarro-Esbri, J., Barragan-Cervera, A., Moles, F. and Peris, B., "Drop-in energy performance evaluation of R1234yf and R1234ze(e) in a vapor compression system as R134a replacements", Applied Thermal Engineering, 71, 259-265, 2014.

7. Meng, Z., Zhang, H., Lei, M., Qin, Y. and Qiu, J., "Performance of low GWP $\mathrm{R} 1234 \mathrm{yf} / \mathrm{R} 134 \mathrm{a}$ mixture as a replacement for R134a in automotive air conditioning systems", International Journal of Heat and Mass Transfer, 116, 362-370, 2018.

8. Li, Z., Liang, K. and Jiang, H., "Experimental study of R1234yf as a drop-in replacement for $\mathrm{R} 134 \mathrm{a}$ in an oil-free refrigeration system", Applied Thermal Engineering, 153, 646-654, 2019.

9. Aral, M.C., Suhermanto, M. and Hosoz, M., "Performance evaluation of an automotive air conditioning and heat pump system using R1234yf and R134a", Science and Technology for the Built Environment, 27, 44-60, 2021.

10. Cho, H., Lee, H. and Park, C., "Performance characteristics of an automobile air conditioning system with internal heat exchanger using refrigerant R1234yf', Applied Thermal Engineering, 61(2), 563-569, 2013.

11. Navarro-Esbri, J., Moles, F. and Barragan-Cervera, A., "Experimental analysis of the internal heat exchanger influence on a vapour compression system performance working with R1234yf as a drop-in replacement for R134a, Applied Thermal Engineering",
59(1-2), 153-161, 2013.

12. Direk, M., Kelesoglu, A. and Akin, A., "Drop-in performance analysis and effect of IHX for an automotive air conditioning system with R1234yf as a replacement of R134a", Journal of Mechanical Engineering, 63(5), 314319, 2017.

13. Wantha, C., "Analysis of heat transfer characteristics of tube-in-tube internal heat exchangers for HFO-1234yf and HFC-134a refrigeration systems", Applied Thermal Engineering, 157, 1-10, 2019.

14. Direk, M. and Kelesoglu, A., "Automotive air conditioning system with an internal heat exchanger using R1234yf and different evaporation and condensation temperatures", Thermal Science, 23(2B), 11151125, 2019.

15. Direk, M., Mert, M.S., Yüksel, F. and Keleşoğlu, A., "Exergetic investigation of R1234yf automotive air conditioning system with internal heat exchanger", International Journal of Thermodynamics, 21(2), 103-108, 2018.

16. Oruç, V. and Devecioğlu, A.G., "Experimental assessment of the retrofit of an internal heat exchanger in refrigeration systems: The effect on energy performance and system operation", Applied Thermal Engineering, 180, 115843, 2020.

17. Prabakaran, R., Lal, D.M. and Devotta, S., "Effect of thermostatic expansion valve tuning on the performance enhancement and environmental impact of a mobile air conditioning system", Journal of Thermal Analysis and Calorimetry, 143, 335-350, 2021. 18. Yataganbaba, A., Kilicarslan, A. and Kurtbas, I., "Exergy analysis of R1234yf and $\mathrm{R} 1234 z e$ as R134a replacements in a two evaporator vapour compression refrigeration system", International Journal of Refrigeration, 60, 26-37, 2015.

19. Vaghela, J.K., "Comparative evaluation of an automobile air-conditioning system using R134a and its alternative refrigerants", Energy Procedia, 109, 153-160, 2017.

20. Gaurav and Kumar, R., "Computational energy and exergy analysis of R134a, R1234yf, R1234ze and their mixtures in vapour compression system", Ain Shams Engineering Journal, 9(4), 3229-3237, 2018.

21. Qi, Z., "Performance improvement 
potentials of R1234yf mobile air conditioning system", International Journal of Refrigeration, 58, 35-40, 2015.

22. Daviran, S., Kasaeian, A., Golzari, S., Mahian, O., Nasirivatan, S. and Wongwises, S., "A comparative study on the performance of HFO-1234yf and HFC-134a as an alternative in automotive air conditioning systems", Applied Thermal Engineering, 110, 1091-1100, 2013.

23. Belman-Flores, J.M. and Ledesma, S., "Statistical analysis of the energy performance of a refrigeration system working with R1234yf using artificial neural networks", Applied Thermal Engineering, 82, 8-17, 2015.

24. Hosoz, M., Kaplan, K., Aral, M.C., Suhermanto, M. and Ertunc, H.M., "Support vector regression modeling of the performance of an R1234yf automotive air conditioning system”, Energy Procedia, 153, 309-314, 2018. 25. Mendoza-Miranda, J.M., SalazarHernandez, C., Carrera-Cerritos, R., RamirezMinguela, J.J., Salazar-Hernandez, M., Navarro-Esbri, J. and Mota-Babiloni, A., "Variable speed liquid chiller drop-in modelling for predictive energy performance of R1234yf as low-GWP refrigerant", International Journal of Refrigeration, 93, 144-158, 2018.

26. Direk, M., Keleşoğlu, A. and Akin, A., "Theoretical performance analysis of an R1234yf refrigeration cycle based on the effectiveness of internal heat exchanger", Hittite Journal of Science and Engineering, 4(1), 2330, 2017.

27. Direk, M. and Yuksel, F., "Experimental evaluation of an automotive heat pump system with R1234yf as an alternative to R134a", Arabian Journal for Science and Engineering, 45, 719-728, 2020.

28. Alkan, A., Kolip, A. and Hosoz, M., "Experimental energy and exergy performance of an automotive heat pump using R1234yf", Journal of Thermal Analysis and Calorimetry, in press, 2020.

29. Tasdemirci, E., Alptekin, E. and Hosoz, M., "Comparative performance of an automobile heat pump system with an internal heat exchanger using R1234yf and R134a", International Journal of Exergy, 33(1), 98-112, 2020.

30. Lemmon, E.W., Huber, M.L. and McLinden, M.O., "Reference fluid thermodynamic and transport properties
(REFPROP), version 9.1, in NIST Standard Reference Database 23", Gaithersburg, National Institute of Standards and Technology, 2013.

31. Moffat, R.J., "Describing the uncertainties in the experimental results", Experimental Thermal and Fluid Science, 1, 317, 1988.

32. Klein, S.A., "EES - Engineering Equation Solver, Version 10.167”, F-Chart Software, http://fchartsoftware.com, 2016. 